\title{
Substituents effects on the corrosion inhibition performance of pyrazolone against carbon steels: quantum chemical and Monte Carlo simulation studies
}

\author{
S. Hadisaputra, ${ }^{1}{ }^{\circ *}$ A.A. Purwoko ${ }^{1} \oplus$ and S. Hamdiani ${ }^{2}$ \\ ${ }^{1}$ Chemistry Education Division, University of Mataram, Jalan Majapahit 62, Mataram, \\ 83125, Indonesia \\ ${ }^{2}$ Department of Applied Chemistry, Chaoyang University of Technology, No. 168, Jifeng E. \\ Rd., Wufeng District, Taichung 41349, Taiwan \\ *E-mail: rizal@unram.ac.id
}

\begin{abstract}
A quantum chemical and Monte Carlo simulation study on substituents' effect on the corrosion inhibition performance of pyrazolone derivatives has been carried out in gas and aqueous phases. Previously, experimental tests of the corrosion inhibition performance of targeted pyrazolone derivatives have been published. However, the experimental study has not explained the mechanism of inhibition of corrosion on metal surfaces. Density functional theory, ab initio MP2 and Monte Carlo simulation are applied as a bridge to understanding the corrosion inhibition mechanism. The interaction patterns and corrosion inhibition mechanisms of pyrazolone derivatives were described using the inhibitor, quantum chemical parameters, Fukui function, and natural bond orbital analysis in the neutral and protonated inhibitor states. A good correlation between the experiment's corrosion inhibition results and the theoretical adsorption energy was obtained and the second-order interaction energy from NBO analysis. The results of the theoretical study are in line with previously published experimental studies. The theoretical research is expected to bridge the gap in designing an effective corrosion inhibitor.
\end{abstract}

Keywords: DFT, ab initio, corrosion inhibition, pyrazolone, Monte Carlo simulation.

Received: February 1, 2021. Published: March 18, 2021

doi: $\underline{10.17675 / 2305-6894-2021-10-1-24}$

\section{Introduction}

Corrosion is a problem that is detrimental to the industry. In the oil industry, for example, corrosion causes damage to metal pipelines [1]. Carbon steel is a metal material widely used in industry because it is much cheaper and has been modified to resist corrosion. However, protective carbon steel needs to be done to prevent the effects of corrosion [2]. Efforts to prevent corrosion on carbon steel are the addition of organic inhibitors. It is the most widely used inhibitor to inhibit various metals' corrosion because it is environmentally friendly [3]. The advantage of organic inhibitors is that they have heteroatoms of $\mathrm{N}, \mathrm{O}, \mathrm{S}$, and $\mathrm{P}$ with high electronic density to be firmly attached to metal surfaces [4]. These factors form a thin film on the metal surface, which will inhibit the corrosion rate [5-7]. Many experimental studies 
on the inhibition efficiency of organic inhibitor corrosion have been reported [8-10]. The addition of substituents to organic corrosion inhibitors such as $\mathrm{OH}, \mathrm{OCH}_{3}, \mathrm{CH}_{3}$, and $\mathrm{NH}_{2}$ can increase corrosion inhibition efficiency $[11,12]$.

Pyrazolone is a 5-membered heterocyclic compound containing two nitrogen atoms and an adjacent carbonyl group $(\mathrm{C}=\mathrm{O})$ (Figure 1) [10]. Pyrazolone can be used as an organic corrosion inhibitor. Cao et al. studied the corrosion inhibition ability of 1-phenyl-3-methyl5-pyrazolone in mild steel in $1 \mathrm{M} \mathrm{HCl}$ solution. The derivative of pyrazolone was able to inhibit corrosion up to $97.2 \%$ [13]. Zhang et al. also studied the corrosion inhibition performance of a pyrazolone derivative, namely 1-phenyl-3-amine-5-pyrazolone on carbon steel in $\mathrm{H}_{2} \mathrm{SO}_{4}$ solution, and obtained an increase in the value of corrosion inhibition efficiency to $98.4 \%$ [14]. Furthermore, the effect of substituents on pyrazolone derivatives on inhibition efficiency has been reported by Fouda et al. It was shown that the substituent $\mathrm{OCH}_{3}$ was more effective at inhibiting corrosion than substituents such as $\mathrm{CH}_{3}$ and $\mathrm{NO}_{2}$ [15].
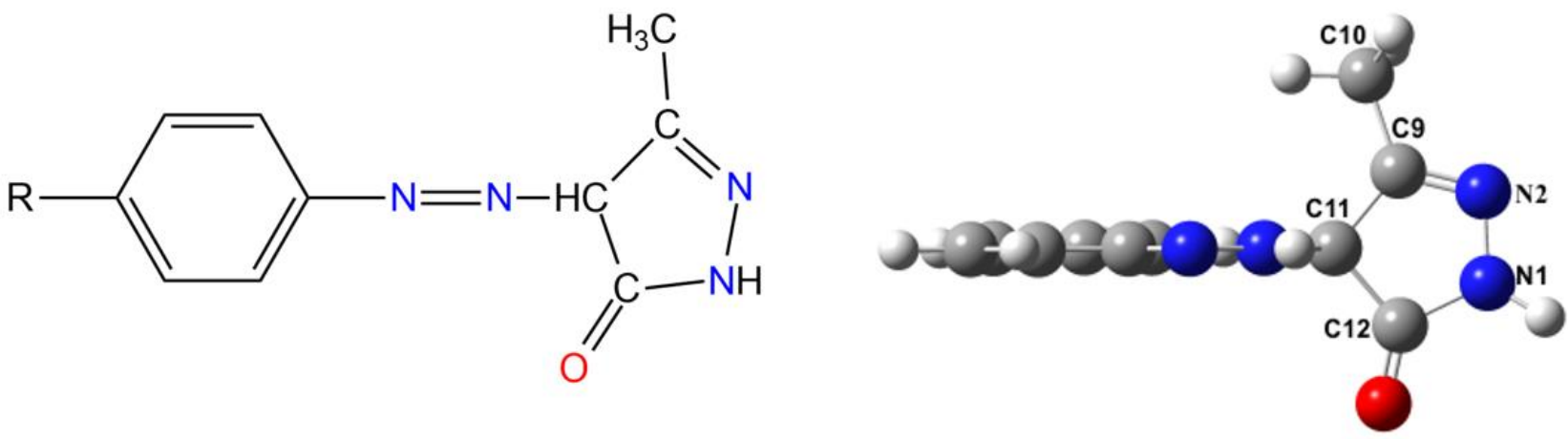

Figure 1. 2D and 3D structure of 5-methyl-4-(phenyldiazenyl)-2,4-dihydro-3H-pyrazol-3-one, where: $\mathrm{R}=\mathrm{H}, \mathrm{CH}_{3}, \mathrm{OCH}_{3}$ and $\mathrm{NO}_{2}$.

Fouda et al. [15], using weight loss and galvanostatic polarization methods, studied substituents' effect on the corrosion inhibition of pyrazolone derivatives against carbon steel. However, this experimental study has limitations, namely that it has not yet explained in detail the mechanism of inhibition by inhibitors on the metal surface. Theoretical studies have proven to provide solutions to similar problems before, in particular on corrosion inhibition. Theoretical research using the density functional theory approach and ab initio can describe the structural properties and inhibition mechanism well [16-18]. Furthermore, molecular dynamics simulations can explain the influence of orientation and structure on the inhibitor interaction pattern on metal surfaces $[19,20]$. This research will focus on a combination of density functional theory, $a b$ initio, and Monte Carlo simulation to explain the interaction mechanism between pyrazolone derivatives and metal surfaces in quantum parameters, Fukui function, and NBO analysis and test the substituent effects on the corrosion performance. 


\section{Methodology}

\section{Quantum chemical calculation}

Theoretical studies based on DFT/B3LYP and ab initio MP2 were carried out at the theoretical level 6 $-311++\mathrm{G}(\mathrm{d}, \mathrm{p})$. DFT was adopted to simulate the molecular properties, reactivity, and selectivity of organic molecules quickly and cheaply [19]. The ab initio method was chosen because it can measure quantum parameters more accurately than DFT [20]. All quantum chemical calculations use Gaussian software 09 [21]. The inhibitor's quantum parameters are the highest occupied molecular orbital HOMO, lowest unoccupied molecular orbital LUMO, ionization potential $I$, electron affinity $A$, electronegativity $\chi$, hardness $\eta$, electron transfer value $\Delta N$. The ionization potential $I$ and the electron affinity $A$ were calculated using the theorem of Koopman [22]. Koopman's theorem is applied to explain the relationship between ionization potential $I$ and electron affinity $A$ with energy levels (HOMO and LUMO energies) according to equations 1 and 2.

$$
\begin{aligned}
& I=-E_{\text {номо }} \\
& A=-E_{\text {LUMO }}
\end{aligned}
$$

Electronegativity $(\chi)$ is the power of an atom or a group of atoms to attract electrons to itself [23], this can be calculated by equation 3:

$$
\chi=\frac{I+A}{2}
$$

Hardness $(\eta)$ can be calculated based on equation (4) as follows [24, 25]:

$$
\eta=\frac{I-A}{2}
$$

Analyze the function of Fukui as the active site in the inhibitor, to determine its reactivity [26]. The analysis of the Fukui function can be calculated using equations 5 and 6 :

$$
\begin{aligned}
& f^{+}(r)=\left(\frac{\partial \rho(r)}{\partial N}\right)_{v(r)}^{+}=\rho_{N+1}(r)-\rho_{N}(r) \\
& f^{-}(r)=\left(\frac{\partial \rho(r)}{\partial N}\right)_{v(r)}^{-}=\rho_{N}(r)-\rho_{N-1}(r)
\end{aligned}
$$

where $\rho_{N+1}(r), \rho_{N}(r)$ and $\rho_{N-1}(r)$ are the electronic density at point $r$ for a system with $N+1$, $N$ and $N-1$ electrons, respectively. $f^{+}(r)$ can be associated with reactivity for nucleophilic attack. It can measure the intramolecular reactivity on the active site of $r$ towards the nucleophilic reagent. $f^{-}(r)$ is associated with reactivity for electrophilic attack and thus serves to measure the intramolecular reactivity in the active site $r$ towards electrophilic reagent [26]. 
According to the Pearson theory $[27,28]$, the value of $\Delta N$ electron transfer from organic molecules to metals can be calculated by equation 7 :

$$
\Delta N=\frac{\chi_{\mathrm{Fe}}-\chi_{\mathrm{inh}}}{2\left(\eta_{\mathrm{Fe}}+\eta_{\mathrm{inh}}\right)},
$$

where $\chi_{\mathrm{Fe}}$ and $\chi_{\text {inh }}$ donate the absolute electronegativity of Fe metal and organic inhibitor molecules while $\eta_{\mathrm{Fe}}$ and $\eta_{\mathrm{inh}}$ are the absolute hardness of iron and organic inhibitor molecules. Therefore, for the theoretical values $\chi_{\mathrm{Fe}}=7.0 \mathrm{eV}$ and $\eta_{\mathrm{Fe}}=0 \mathrm{eV}$ to calculate the number of electrons transferred [28, 29].

Electron delocalization interactions can be seen quantitatively using the stabilization energy $\left(E^{2}\right)$, which can be estimated based on the theory of "The second-order perturbation." Stabilization energy can be formulated by equation 8 :

$$
E^{2}=\Delta E_{i, j}=q_{i} \frac{F^{2}}{E_{i}-E_{j}},
$$

where $E^{2}$ is the stabilization energy, $q_{i}$ denotes the donor orbitals' location, $E_{i}$ and $E_{j}$ are the donor and acceptor energies of NBO, and $F_{i, j}$ is the Fock matrix elements between the orbitals of $\mathrm{NBO} i$ and $j[30,31]$.

\section{Monte Carlo simulation}

The organic inhibitor adsorption of pyrazolone derivatives with the addition of substituents on the carbon steel surface was theoretically modeled using the Monte Carlo (MC) simulation approach. Monte Carlo simulation of pyrazolone derivatives with the addition of substituents from 100 water molecules using Material Studio 7.0 [32]. Optimization is done with the forcite module using the COMPASS force field. The surface of carbon steel can be represented by the $\mathrm{Fe}(110)$ plane, which has been done before because the $\mathrm{Fe}(110)$ crystalline plane is the most stable and has a moderate Fe atomic density [33]. The $\mathrm{Fe}(110)$ field is then enlarged to become a supercell $(8 \times 8)$. After that, a vacuum plate with a thickness of $8.0 \mathrm{~nm}$ was built up in the $\mathrm{Fe}(110)$ plane. The adsorption energy $\left(E_{\text {ads }}\right)$ of the most stable conformation of the inhibitor/Fe(110) is obtained in the neutral and protonated state of each pyrazolone derivative compound with the addition of substituents $\left(\mathrm{H}, \mathrm{CH}_{3}, \mathrm{OCH}_{3}\right.$, and $\left.\mathrm{NO}_{2}\right)$.

\section{Results and Discussion}

As a consequence of choosing the DFT and ab initio methods, the accuracy of calculations must be validated by comparing theoretical and experimental calculations. The comparison of the pyrazolone crystal structure published previously with the results of theoretical studies [34] can be seen in Table 1. Table 1 shows the pyrazolone derivatives' geometrical parameters calculated using DFT and ab initio MP2 based on $6-311++\mathrm{G}(\mathrm{d}, \mathrm{p})$ level of theory. A reasonably low difference between experimental and theoretical studies was obtained, the difference from the bond distance was obtained at $0.03327 \AA$, and the bond 
angle obtained $2.4598^{\circ}$. It shows that the two methods with the theoretical level can be appropriately used to explain the compounds studied.

Table 1. Comparison of the crystal structure of experimental pyrazolone derivatives [34] vs. theoretical B3LYP/6-311++G(d, p).

\begin{tabular}{cccccc}
\hline Bond & Exp [34] & Theory & Bond angle & Exp [34] & Theory \\
\hline N1-N2 & 1.407 & 1.3918 & N2-C9-C11 & 114.9 & 112.7294 \\
N2-C9 & 1.284 & 1.2883 & C9-C11-C12 & 104.5 & 100.9127 \\
C9-C10 & 1.487 & 1.4911 & N1-C12-C11 & 99.7 & 103.2395 \\
C9-C11 & 1.482 & 1.5175 & N1-N2-C9 & 107.2 & 107.7422 \\
C11-C12 & 1.540 & 1.5550 & & & \\
N1-C12 & 1.501 & 1.3755 & & & \\
\hline
\end{tabular}

The quantum chemical parameters show that the presence of heteroatoms $(\mathrm{N}, \mathrm{O})$ and $\pi$ bonds in pyrazolone derivatives increases their corrosion inhibition performance against carbon steel. Quantum chemical parameters can be used to determine pyrazolone's theoretical chemical properties so that quantum parameters can be used to predict the corrosion inhibition efficiency of pyrazolone derivatives. The addition of substituents $\left(\mathrm{CH}_{3}\right.$, $\mathrm{OCH}_{3}$, and $\mathrm{NO}_{2}$ ) affect the value of corrosion inhibition efficiency [15]. As a consequence of the inhibitor's application to the acid medium, apart from the neutral molecule's electronic properties, the electronic properties of the protonated form of the inhibitor were also investigated. The electron-rich sites of inhibitors such as oxygen, nitrogen, and carbon atoms sharing multiple bonds become protonated. The most likely protonated sites are found based on the protonation affinity and basicity. The quantum chemical parameters (such as HOMO energy level, ionization potential, electronegativity, and electron transfer), neutral and protonated inhibitors are shown in Tables $2-5$.

HOMO energy shows the ease of the nature of the molecule to donate its electrons; the greater the energy value of the HOMO, the stronger the inhibitor is to adhere to the metal surface so that it can increase the efficiency of corrosion inhibition [24]. The high energy level of HOMO in the inhibitor can more easily donate its lone pair and $\pi$ bonds to iron atoms to interact to form complex compounds [24]. In general (Table 2-5), the highest HOMO energy level value of the pyrazolone derivative was obtained for the $\mathrm{OCH}_{3}$ substituent of $-8.7060 \mathrm{eV}$, higher than the other substituents $\left(\mathrm{H}, \mathrm{CH}_{3}\right.$, and $\left.\mathrm{NO}_{2}\right)$. The order of the HOMO energy levels is $\mathrm{OCH}_{3}>\mathrm{CH}_{3}>\mathrm{H}>\mathrm{NO}_{2}$. The high HOMO energy level on the $\mathrm{OCH}_{3}$ substituent indicates that the inhibitor readily donates more lone pairs to the ferrous metal to interact to form complexes with the metal surface. The interactions that occur will be stronger and have a good effect on the inhibitory power of corrosion. 

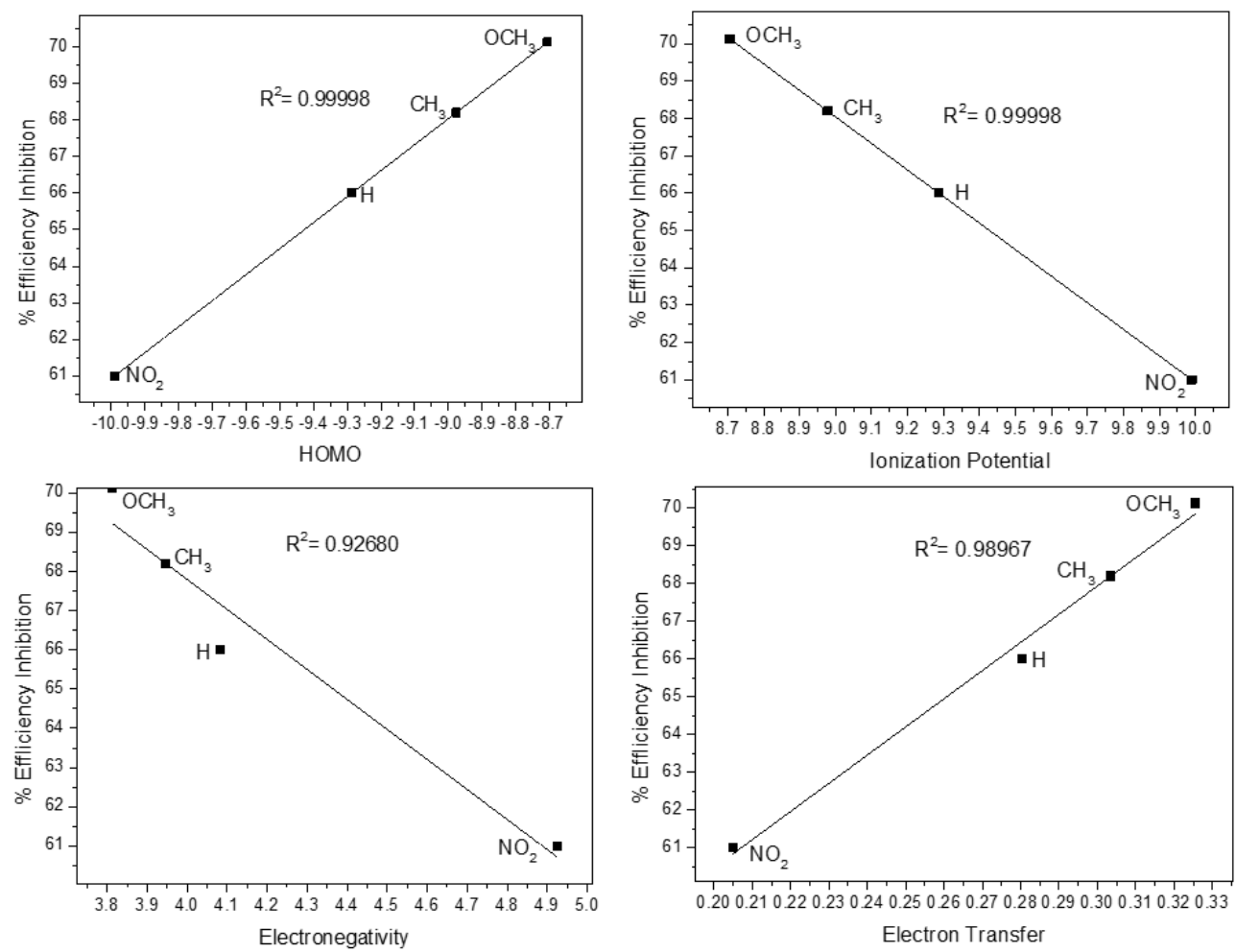

Figure 2. The relationship between the inhibition efficiency of pyrazolone derivatives and quantum parameters in the neutral form.
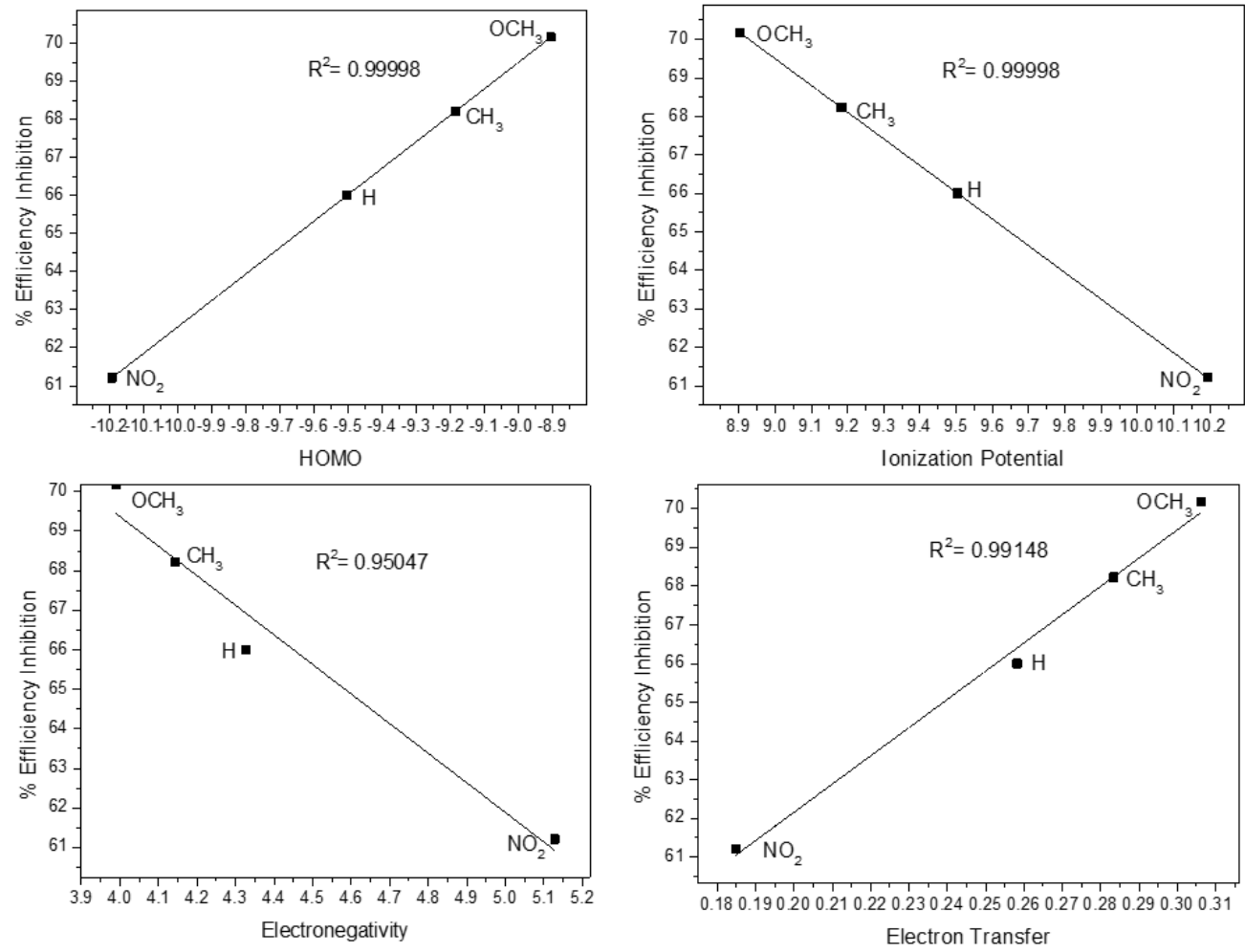

Figure 3. The relationship between the inhibition efficiency of pyrazolone derivatives and quantum parameters in the protonated form. 
Table 2. The quantum chemical parameters of pyrazolone derivatives and the effect of the substituent calculated using B3LYP and MP2 with the 6-311++G(d,p) basis set in gas medium.

\begin{tabular}{|c|c|c|c|c|c|c|c|c|}
\hline$-\mathbf{R}$ & $E_{\text {номо }}$ & $E_{\text {LUMO }}$ & $\Delta \boldsymbol{E}$ & $I$ & $A$ & $\chi$ & $\eta$ & $\Delta N$ \\
\hline \multicolumn{9}{|l|}{$\mathbf{H}$} \\
\hline $\begin{array}{c}\text { B3LYP/6- } \\
311++\mathrm{G}(\mathrm{d}, \mathrm{p})\end{array}$ & -6.9092 & -2.5505 & -4.3587 & 6.9092 & 2.5505 & 4.7299 & 2.1794 & 0.5208 \\
\hline $\begin{array}{c}\mathrm{MP} 2 / 6- \\
311++\mathrm{G}(\mathrm{d}, \mathrm{p})\end{array}$ & -9.2440 & 0.9804 & -10.2244 & 9.244 & -0.9804 & 4.1318 & 5.1122 & 0.2805 \\
\hline \multicolumn{9}{|l|}{$\mathrm{CH}_{3}$} \\
\hline $\begin{array}{c}\text { B3LYP/6- } \\
311++\mathrm{G}(\mathrm{d}, \mathrm{p})\end{array}$ & -6.8099 & -2.4338 & -4.3761 & 6.8099 & 2.4338 & 4.6219 & 2.1881 & 0.5434 \\
\hline $\begin{array}{c}\mathrm{MP} 2 / 6- \\
311++\mathrm{G}(\mathrm{d}, \mathrm{p})\end{array}$ & -8.9278 & 0.9595 & -9.8873 & 8.9278 & -0.9595 & 3.9842 & 4.9436 & 0.305 \\
\hline \multicolumn{9}{|l|}{$\mathrm{OCH}_{3}$} \\
\hline $\begin{array}{c}\text { B3LYP/6- } \\
311++G(d, p)\end{array}$ & -6.472 & -2.3353 & -4.1367 & 6.472 & 2.3353 & 4.4036 & 2.0683 & 0.6276 \\
\hline $\begin{array}{c}\mathrm{MP} 2 / 6- \\
311++\mathrm{G}(\mathrm{d}, \mathrm{p})\end{array}$ & -8.6211 & 0.9151 & -9.5362 & 8.6211 & -0.9151 & 3.853 & 4.7681 & 0.3300 \\
\hline \multicolumn{9}{|l|}{$\mathrm{NO}_{2}$} \\
\hline $\begin{array}{c}\text { B3LYP/6- } \\
311++G(d, p)\end{array}$ & -7.2929 & -3.5884 & -3.7046 & 7.2929 & 3.5884 & 5.4406 & 1.8523 & 0.4209 \\
\hline $\begin{array}{c}\mathrm{MP} 2 / 6- \\
311++\mathrm{G}(\mathrm{d}, \mathrm{p})\end{array}$ & -10.1637 & 0.0778 & -10.2416 & 10.1637 & -0.0778 & 5.043 & 5.1208 & 0.1911 \\
\hline
\end{tabular}

Table 3. Quantum chemical parameters of neutral pyrazolone derivatives calculated using B3LYP/6$311++\mathrm{G}(\mathrm{d}, \mathrm{p})$ and MP2/6-311++G(d, p) in the aqueous medium.

\begin{tabular}{|c|c|c|c|c|c|c|c|c|}
\hline$-\mathbf{R}$ & $\boldsymbol{E}_{\text {номо }}$ & $\boldsymbol{E}_{\text {LUMO }}$ & $\Delta \boldsymbol{E}$ & $I$ & $A$ & $\chi$ & $\eta$ & $\Delta N$ \\
\hline \multicolumn{9}{|l|}{$\mathbf{H}$} \\
\hline $\begin{array}{c}\text { B3LYP/6- } \\
311++G(d, p)\end{array}$ & -7.0442 & -2.655 & -4.3892 & 7.0442 & 2.655 & 4.8496 & 2.1946 & 0.4899 \\
\hline $\begin{array}{c}\mathrm{MP} 2 / 6- \\
311++\mathrm{G}(\mathrm{d}, \mathrm{p})\end{array}$ & -9.287 & 1.1227 & -10.4097 & 9.287 & -1.1227 & 4.0821 & 5.2049 & 0.2803 \\
\hline \multicolumn{9}{|l|}{$\mathrm{CH}_{3}$} \\
\hline $\begin{array}{c}\text { B3LYP/6- } \\
311++\mathrm{G}(\mathrm{d}, \mathrm{p})\end{array}$ & -6.9239 & -2.5707 & -4.3533 & 6.9239 & 2.5707 & 4.7473 & 2.1766 & 0.5175 \\
\hline
\end{tabular}




\begin{tabular}{ccccccccc}
\hline$-\mathbf{R}$ & $\boldsymbol{E}_{\text {номо }}$ & $\boldsymbol{E}_{\text {LUMо }}$ & $\Delta \boldsymbol{E}$ & $\boldsymbol{I}$ & $\boldsymbol{A}$ & $\chi$ & $\boldsymbol{\eta}$ & $\Delta \boldsymbol{N}$ \\
\hline $\begin{array}{c}\text { MP2/6- } \\
311++\mathrm{G}(\mathrm{d}, \mathrm{p})\end{array}$ & -8.9776 & 1.0852 & -10.0628 & 8.9776 & -1.0852 & 3.9462 & 5.0314 & 0.3035 \\
\hline OCH3 & & & & & & & & \\
\hline $\begin{array}{c}\text { B3LYP/6- } \\
\text { 311++G(d,p) } \\
\text { MP2/6- }\end{array}$ & -6.5446 & -2.5013 & -4.0433 & 6.5446 & 2.5013 & 4.5229 & 2.0217 & 0.6126 \\
$311++\mathrm{G}(\mathrm{d}, \mathrm{p})$ & -8.706 & 1.0787 & -9.7847 & 8.706 & -1.0787 & 3.8137 & 4.8923 & 0.3256 \\
\hline NO2 & & & & & & & & \\
\hline $\begin{array}{c}\text { B3LYP/6- } \\
\text { 311++G(d,p) }\end{array}$ & -7.149 & -3.5658 & -3.5832 & 7.149 & 3.5658 & 5.3574 & 1.7916 & 0.4584 \\
$\begin{array}{c}\text { MP2/6- } \\
\text { 311++G(d,p) }\end{array}$ & -9.9901 & 0.1415 & -10.1316 & 9.9901 & -0.1415 & 4.9243 & 5.0658 & 0.2049 \\
\hline
\end{tabular}

Table 4. Quantum chemical parameters of protonated pyrazolone derivatives calculated using B3LYP/6$311++\mathrm{G}(\mathrm{d}, \mathrm{p})$ and MP2/6-311++G(d, p) in the gas phase.

\begin{tabular}{|c|c|c|c|c|c|c|c|c|}
\hline$-\mathbf{R}$ & $E_{\text {номо }}$ & $E_{\text {LUMO }}$ & $\Delta E$ & $I$ & $\boldsymbol{A}$ & $\chi$ & $\eta$ & $\Delta \mathbf{N}$ \\
\hline \multicolumn{9}{|l|}{ Protonated H } \\
\hline $\begin{array}{c}\text { B3LYP/6- } \\
311++G(d, p)\end{array}$ & -10.0718 & -7.1776 & -2.8942 & 10.0718 & 7.1776 & 8.6247 & 1.4471 & -0.5613 \\
\hline $\begin{array}{c}\mathrm{MP} 2 / 6- \\
311++\mathrm{G}(\mathrm{d}, \mathrm{p})\end{array}$ & -12.0168 & -2.9745 & -9.0423 & 12.0168 & 2.9745 & 7.4957 & 4.5212 & -0.0548 \\
\hline \multicolumn{9}{|l|}{ Protonated $\mathrm{CH}_{3}$} \\
\hline $\begin{array}{c}\text { B3LYP/6- } \\
311++G(d, p)\end{array}$ & -9.7286 & -7.079 & -2.6496 & 9.7286 & 7.079 & 8.4038 & 1.3248 & -0.5298 \\
\hline $\begin{array}{c}\mathrm{MP} 2 / 6- \\
311++\mathrm{G}(\mathrm{d}, \mathrm{p})\end{array}$ & -11.6225 & -2.8953 & -8.7272 & 11.6225 & 2.8953 & 7.2589 & 4.3636 & -0.0297 \\
\hline \multicolumn{9}{|c|}{ Protonated $\mathrm{OCH}_{3}$} \\
\hline $\begin{array}{c}\text { B3LYP/6- } \\
311++G(d, p)\end{array}$ & -9.21 & -6.9901 & -2.2199 & 9.21 & 6.9901 & 8.100 & 1.1100 & -0.4955 \\
\hline $\begin{array}{c}\mathrm{MP} 2 / 6- \\
311++\mathrm{G}(\mathrm{d}, \mathrm{p})\end{array}$ & -11.2759 & -2.8561 & -8.4198 & 11.2759 & 2.8561 & 7.066 & 4.2099 & -0.0078 \\
\hline \multicolumn{9}{|l|}{ Protonated $\mathrm{NO}_{2}$} \\
\hline $\begin{array}{c}\text { B3LYP/6- } \\
311++G(d, p)\end{array}$ & -10.6609 & -7.506 & -3.1549 & 10.6609 & 7.506 & 9.0834 & 1.5774 & -0.6604 \\
\hline
\end{tabular}




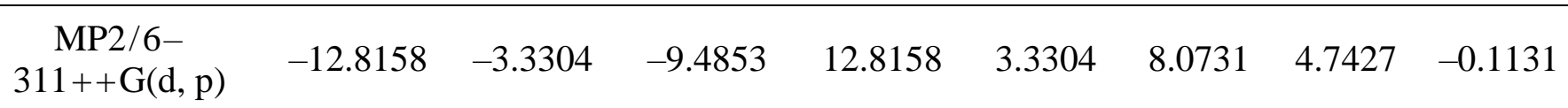

Table 5. Quantum chemical parameters of protonated pyrazolone derivatives calculated using B3LYP/6$311++\mathrm{G}(\mathrm{d}, \mathrm{p})$ and $\mathrm{MP} 2 / 6-311++\mathrm{G}(\mathrm{d}, \mathrm{p})$ in the aqueous medium.

\begin{tabular}{|c|c|c|c|c|c|c|c|c|}
\hline$-\mathbf{R}$ & $E_{\text {номо }}$ & $E_{\text {Lumo }}$ & $\Delta \boldsymbol{E}$ & $I$ & $A$ & $\chi$ & $\eta$ & $\Delta N$ \\
\hline \multicolumn{9}{|l|}{ Protonated $\mathbf{H}$} \\
\hline $\begin{array}{c}\text { B3LYP/6- } \\
311++\mathrm{G}(\mathrm{d}, \mathrm{p})\end{array}$ & -7.4801 & -3.3312 & -4.1489 & 7.4801 & 3.3312 & 5.4057 & 2.0745 & 0.3843 \\
\hline $\begin{array}{c}\mathrm{MP} 2 / 6- \\
311++\mathrm{G}(\mathrm{d}, \mathrm{p})\end{array}$ & -9.5036 & 0.8523 & -10.3558 & 9.5036 & -0.8523 & 4.3257 & 5.1779 & 0.2582 \\
\hline \multicolumn{9}{|l|}{ Protonated $\mathrm{CH}_{3}$} \\
\hline $\begin{array}{c}\mathrm{B} 3 \mathrm{LYP} / 6- \\
311++\mathrm{G}(\mathrm{d}, \mathrm{p})\end{array}$ & -7.2029 & -3.3054 & -3.8975 & 7.2029 & 3.3054 & 5.2541 & 1.9487 & 0.448 \\
\hline $\begin{array}{c}\mathrm{MP} 2 / 6- \\
311++\mathrm{G}(\mathrm{d}, \mathrm{p})\end{array}$ & -9.1828 & 0.8969 & -10.0796 & 9.1828 & -0.8969 & 4.1429 & 5.0398 & 0.2834 \\
\hline \multicolumn{9}{|l|}{ Protonated $\mathrm{OCH}_{3}$} \\
\hline $\begin{array}{c}\text { B3LYP/6- } \\
311++G(d, p)\end{array}$ & -6.7642 & -3.2746 & -3.4896 & 6.7642 & 3.2746 & 5.0194 & 1.7448 & 0.5676 \\
\hline $\begin{array}{c}\text { MP2/6- } \\
311++G(d, p)\end{array}$ & -8.9036 & 0.9241 & -9.8277 & 8.9036 & -0.9241 & 3.9897 & 4.9138 & 0.3063 \\
\hline \multicolumn{9}{|l|}{ Protonated $\mathrm{NO}_{2}$} \\
\hline $\begin{array}{c}\text { B3LYP/6- } \\
311++G(d, p)\end{array}$ & -7.7792 & -3.7982 & -3.981 & 7.7792 & 3.7982 & 5.7887 & 1.9905 & 0.3043 \\
\hline $\begin{array}{c}\mathrm{MP} 2 / 6- \\
311++\mathrm{G}(\mathrm{d}, \mathrm{p})\end{array}$ & -10.1934 & -0.0634 & -10.13 & 10.1934 & 0.0634 & 5.1284 & 5.065 & 0.1848 \\
\hline
\end{tabular}

Previous research reported by Fouda et al. showed that substituents' presence changed pyrazolone corrosion inhibition efficiency. The $\mathrm{OCH}_{3}$ substituent addition was more efficient at inhibiting carbon steel corrosion in a hydrochloric acid medium (Figure 4). This substituent increases the nitrogen atoms' electron density due to the mesomeric effect, which facilitates the stronger adsorption of the $\mathrm{OCH}_{3}$-substituted pyrazole on the carbon steel surface. It may explain why the inhibition efficiency of $\mathrm{OCH}_{3}$ is higher than that of $\mathrm{H}, \mathrm{CH}_{3}$, and $\mathrm{NO}_{2}$ [12]. It is consistent with previous reports on $\mathrm{NO}_{2}$ substituted benzimidazole, which reduced corrosion inhibition efficiency values [12].

The low ionization potential indicates that it is easy for an atom to remove its outer electrons so that it is easy to donate electrons from the molecule to the metal surface. This high electron donor rate increases the efficiency of corrosion inhibition. The high ionization 
potential indicates that the electrons do not easily escape from the outer shell, which implies the electron transfer process's difficulty to the surface of the ferrous metal $(\mathrm{Fe})$. This process reduces the efficiency of corrosion inhibition. Table 2-5 shows the lowest ionization potential value of $\mathrm{OCH}_{3}-$ substituted pyrazolone of $8.7060 \mathrm{eV}$ calculated using B3LYP/6$311++\mathrm{G}(\mathrm{d}, \mathrm{p})$. Main-Bobo et al. reported that pyrazolone's potential ionization value using photoionization mass spectrometry was $9.25 \mathrm{eV}$ [35]. It shows that B3LYP/6-311++G(d, p) has not approached the experimental results. Thus, the theoretical computations' quality was improved using MP2/6-311++G(d, p). The value of the pyrazolone ionization potential of $9.2870 \mathrm{eV}$ was obtained in the MP2/6-311++G(d,p) method. Even though the values differ, the trend between the two methods still shows that $\mathrm{OCH}_{3}$ has the greatest influence on corrosion inhibition efficiency. $\mathrm{OCH}_{3}$ is more reactive to iron and causes a strong interaction between the inhibitor and the metal surface. The strength of this reaction has an impact on the high value of the corrosion inhibition efficiency.

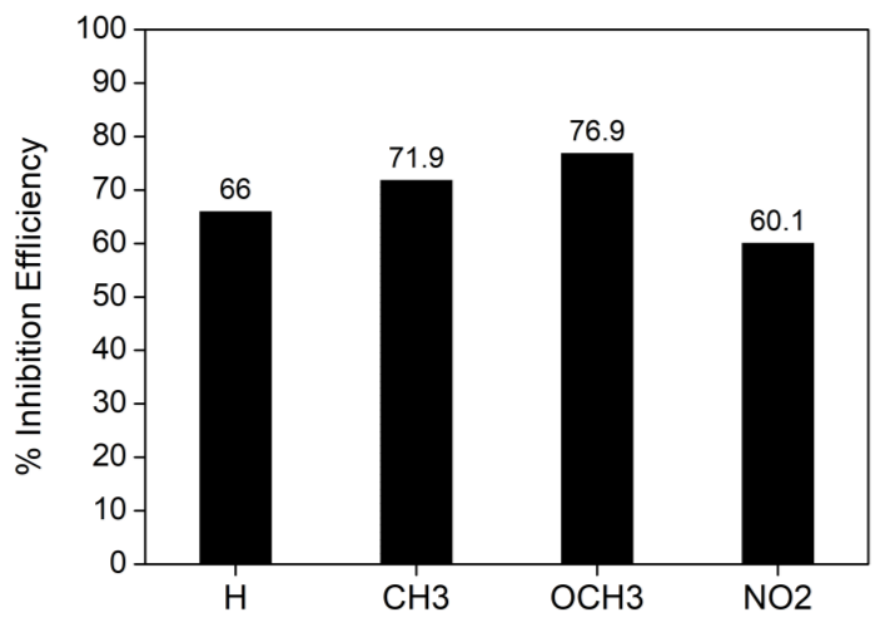

Figure 4. The corrosion inhibition efficiency values of several pyrazolone derivatives in experimental studies [15].

In the interaction between inhibitors and metals, electrons from molecules with low electronegativity will move towards a high electronegativity molecule. The small electronegativity of a molecule makes it easy for the molecule to donate electrons to become more reactive. Conversely, a considerable electronegativity value indicates the molecule to be unreactive [25]. Theoretically, iron metal's electronegativity value $(7 \mathrm{eV})$ is higher than the electronegativity value of pyrazolone derivatives such as $\mathrm{OCH}_{3}, 3.8137 \mathrm{eV}$, so it tends to release electrons. The electronegativity values can be seen in Table $2-5$, which shows that $\mathrm{OCH}_{3}$ has a high corrosion inhibiting efficiency compared to the pyrazolone substituted $\mathrm{CH}_{3}$ and $\mathrm{NO}_{2}$.

Electron transfer will occur from the inhibitor to the metal surface if $\Delta N$ is positive and the value is less than $\Delta N<3.6$, so that the value of inhibition efficiency is high [36]. An electron-donating group can increase corrosion inhibition efficiency because it can increase electrons' transfer to the metal surface. According to Koopman (1934), the highest electron 
transfer value $(\Delta N)$ will produce the best inhibitor efficiency [23]. Tables 2-5 show the value of the electron transfer amount of the pyrazolone derivative. The high electron transfer value is again demonstrated by the $\mathrm{OCH}_{3}$ substituted pyrazolone of $0.3256 \mathrm{eV}$. These results are consistent with the results of previous experiments reported by Fouda et al.

Figure 5 shows the shape of the HOMO and LUMO orbitals, and electrostatic potential (ESP) distribution of the respective inhibitors. Electron rich inhibitors capable of donating electrons to metal surfaces increase their ability to inhibit corrosion in carbon steels [22]. The HOMO orbital can be distributed evenly with the molecule's electrons, whereas the LUMO orbital has an anti-bonding character [23]. The electron density indicates that a negative charge in red is easily delocalized on the $\mathrm{N}$ atom because of the lone pair. Figure 5 also shows the molecular ESP inhibitors. ESP is an opportunity to find the distribution of electron charges in coordinates $(x, y$, and $z)$ in a molecule. ESP is closely related to electron density to explain molecules' properties, predict molecular structure, bond strength, reactivity, and stability. ESP shows the active site of the pyrazolone derivative, which has aromatic and heteroatoms in its structure. Figure 5 shows that the blue and red colors can represent both electron-poor and electron-rich regions. It appears that the active sites of the pyrazolone derivative are aromatic regions and nitrogen heteroatoms.

Fukui function analysis is an index that distinguishes each part of a molecule based on its characteristic properties. Each molecule has a different active site so that the function of Fukui can be used to find a picture of the active site that can be used in interaction. The nucleophilic and electrophilic attacks can be controlled by the maximum values of $f^{+}$and $f^{-}$ $[37,38]$. The greater the Fukui function's value, the more reactive the active side of a molecule is. The $f^{+}$symbol indicates the ability of an inhibitor to accept electrons from a metal surface.

On the other hand, the symbol $f^{-}$denotes electrons' donation to the empty orbital in the metal by the inhibitor [39]. Table 6 shows the function of the pyrazolone derivative Fukui. High $f^{+}$values are found in $\mathrm{C}(1), \mathrm{N}(7)$, and $\mathrm{N}(8)$ atoms, so that these atoms are predicted to experience a back donation from the Fe atom. High $f^{-}$values are found in $\mathrm{C}(10), \mathrm{N}(8)$, and $\mathrm{O}(18)$ atoms. It shows that the atom donates its electrons to the $\mathrm{Fe}$ atom so that coordination covalent bonds occur.

Table 6. Fukui functional analysis of pyrazolone derivatives.

\begin{tabular}{ccccccc}
\hline$-\mathbf{R}$ & Atom & $\boldsymbol{N}-$ & $\boldsymbol{N}$ & $\boldsymbol{N}+$ & $\boldsymbol{f}^{+}$ & $\boldsymbol{f}^{-}$ \\
\hline $\mathbf{H}$ & $\mathrm{C} 1$ & -0.17461 & -0.30409 & -0.39428 & -0.09019 & -0.12948 \\
\hline & $\mathrm{C} 2$ & -0.18812 & -0.12862 & -0.11335 & 0.01526 & 0.05951 \\
& $\mathrm{C} 3$ & -0.19955 & -0.16665 & -0.14560 & 0.02104 & 0.03290 \\
& $\mathrm{C} 4$ & -0.38056 & -0.31630 & -0.27974 & 0.03656 & 0.06426 \\
& C5 & -0.35667 & -0.31714 & -0.28420 & 0.03294 & 0.03953 \\
& C6 & 0.03552 & 0.15797 & 0.23052 & 0.07255 & 0.12245 \\
\hline
\end{tabular}




\begin{tabular}{|c|c|c|c|c|c|c|}
\hline$-\mathbf{R}$ & Atom & $N-$ & $N$ & $N+$ & $f^{+}$ & $f^{-}$ \\
\hline & N7 & -0.20155 & 0.04694 & 0.18442 & 0.13748 & 0.24850 \\
\hline & N8 & -0.06986 & 0.20687 & 0.39301 & 0.18614 & 0.27672 \\
\hline & C9 & -0.20037 & -0.39309 & -0.48249 & -0.08940 & -0.19272 \\
\hline & $\mathrm{C} 10$ & 0.25742 & 0.29380 & 0.34634 & 0.05254 & 0.03638 \\
\hline & $\mathrm{C} 11$ & -0.69783 & -0.71997 & -0.74721 & -0.02724 & -0.02214 \\
\hline & N12 & -0.14044 & -0.09881 & 0.01321 & 0.11202 & 0.04163 \\
\hline & $\mathrm{C} 13$ & 0.12092 & 0.16179 & 0.16603 & 0.00424 & 0.04088 \\
\hline & $\mathrm{O} 14$ & -0.45483 & -0.40963 & -0.28436 & 0.12527 & 0.0452 \\
\hline & N15 & -0.20628 & -0.19289 & -0.10544 & 0.08744 & 0.0134 \\
\hline \multirow[t]{16}{*}{$\mathrm{CH}_{3}$} & $\mathrm{C} 1$ & -0.10492 & -0.57179 & -0.61237 & -0.04057 & -0.46687 \\
\hline & $\mathrm{C} 2$ & 0.06551 & -0.29437 & -0.26023 & 0.03414 & -0.35988 \\
\hline & $\mathrm{C} 3$ & -0.04023 & -0.56967 & -0.56151 & 0.00816 & -0.52944 \\
\hline & $\mathrm{C} 4$ & 0.16079 & 0.56023 & 0.65367 & 0.09344 & 0.39944 \\
\hline & $\mathrm{C} 5$ & -0.06573 & -0.18354 & -0.09125 & 0.09229 & -0.11781 \\
\hline & C6 & 0.26456 & 0.24128 & 0.31384 & 0.07257 & -0.02329 \\
\hline & N7 & 0.24618 & 0.03546 & 0.13748 & 0.10201 & -0.21072 \\
\hline & N8 & 0.46306 & 0.23330 & 0.36069 & 0.12739 & -0.22977 \\
\hline & $\mathrm{C} 9$ & -0.04279 & -0.34642 & -0.40007 & -0.05365 & -0.30363 \\
\hline & $\mathrm{C} 10$ & 0.03025 & 0.27465 & 0.29227 & 0.01762 & 0.24441 \\
\hline & $\mathrm{C} 11$ & -0.00687 & -0.72675 & -0.74503 & -0.01828 & -0.71988 \\
\hline & N12 & 0.00961 & -0.10068 & -0.03231 & 0.06837 & -0.11029 \\
\hline & $\mathrm{C} 13$ & 0.03295 & 0.15893 & 0.16065 & 0.00172 & 0.12598 \\
\hline & O14 & 0.00230 & -0.4104 & -0.33127 & 0.07913 & -0.4127 \\
\hline & N15 & 0.00345 & -0.19391 & -0.15568 & 0.03823 & -0.19736 \\
\hline & C16 & -0.01893 & -0.58765 & -0.59429 & -0.00663 & -0.56872 \\
\hline \multirow[t]{7}{*}{$\mathrm{OCH}_{3}$} & $\mathrm{C} 1$ & -0.37451 & -0.54405 & 0.33104 & 0.87509 & -0.16955 \\
\hline & $\mathrm{C} 2$ & 0.00310 & 0.07163 & -0.11080 & -0.18244 & 0.06853 \\
\hline & C3 & -0.44546 & -0.44329 & 0.13968 & 0.58298 & 0.00217 \\
\hline & $\mathrm{C} 4$ & -0.49963 & -0.49621 & 0.17327 & 0.66948 & 0.00342 \\
\hline & $\mathrm{C} 5$ & 0.18397 & 0.26946 & 0.09370 & -0.17576 & 0.08549 \\
\hline & C6 & -0.01215 & 0.15326 & -0.01428 & -0.16754 & 0.16541 \\
\hline & N7 & -0.24030 & 0.00918 & -0.10565 & -0.11483 & 0.24948 \\
\hline
\end{tabular}




\begin{tabular}{|c|c|c|c|c|c|c|}
\hline$-\mathbf{R}$ & Atom & $N-$ & $N$ & $N+$ & $f^{+}$ & $f^{-}$ \\
\hline & N8 & -0.04855 & 0.23091 & 0.18981 & -0.04110 & 0.27946 \\
\hline & C9 & -0.14078 & -0.32990 & -0.00150 & 0.32841 & -0.18912 \\
\hline & $\mathrm{C} 10$ & 0.23252 & 0.26600 & 0.00729 & -0.25871 & 0.03348 \\
\hline & $\mathrm{C} 11$ & -0.69799 & -0.72035 & 0.00248 & 0.72283 & -0.02236 \\
\hline & N12 & -0.14405 & -0.10245 & 0.01689 & 0.11934 & 0.04159 \\
\hline & $\mathrm{C} 13$ & 0.11617 & 0.15996 & 0.00511 & -0.15485 & 0.04379 \\
\hline & O14 & -0.45670 & -0.41385 & 0.02874 & 0.44259 & 0.04285 \\
\hline & N15 & -0.20413 & -0.19185 & 0.01360 & 0.20544 & 0.01228 \\
\hline \multirow[t]{18}{*}{$\mathrm{NO}_{2}$} & $\mathrm{C} 1$ & -0.44392 & -0.49188 & 0.57678 & 1.06865 & -0.04796 \\
\hline & $\mathrm{C} 2$ & -0.32929 & -0.28346 & -0.27102 & 0.01245 & 0.04583 \\
\hline & $\mathrm{C} 3$ & -0.14786 & -0.05565 & -0.04038 & 0.01526 & 0.09221 \\
\hline & $\mathrm{C} 4$ & -0.33718 & -0.49117 & -0.51118 & -0.02001 & -0.15399 \\
\hline & $\mathrm{C} 5$ & -0.23424 & -0.13112 & -0.11320 & 0.01791 & 0.10312 \\
\hline & C6 & 0.36895 & 0.49241 & 0.55934 & 0.06693 & 0.12346 \\
\hline & N7 & -0.07025 & 0.03838 & 0.12724 & 0.08886 & 0.10864 \\
\hline & N8 & 0.13992 & 0.28991 & 0.42870 & 0.13879 & 0.14999 \\
\hline & C9 & -0.30986 & -0.39455 & -0.44297 & -0.04841 & -0.08470 \\
\hline & $\mathrm{C} 10$ & 0.27822 & 0.29170 & 0.37272 & 0.08102 & 0.01348 \\
\hline & $\mathrm{C} 11$ & -0.71161 & -0.72090 & -0.74882 & -0.02792 & -0.00929 \\
\hline & N12 & -0.11630 & -0.09287 & 0.04512 & 0.13799 & 0.02342 \\
\hline & C13 & 0.14292 & 0.15591 & 0.14425 & -0.01165 & 0.01299 \\
\hline & O14 & -0.42580 & -0.39716 & -0.22877 & 0.16839 & 0.02864 \\
\hline & N15 & -0.19785 & -0.18943 & -0.05462 & 0.13481 & 0.00842 \\
\hline & N16 & -0.16780 & -0.10832 & -0.09977 & 0.00855 & 0.05949 \\
\hline & O17 & -0.22120 & -0.05979 & -0.04914 & 0.01065 & 0.16141 \\
\hline & O18 & -0.21573 & -0.05387 & -0.04285 & 0.01102 & 0.16186 \\
\hline
\end{tabular}

Natural Bond Orbital NBO analysis indicates the strength of the interaction between atoms, which involves the amount of charge transfer and affects molecular stability. Analysis of NBO as the second-order interaction energy $E^{2}$ can be used to determine the orbital filled with electrons or empty, which contributes to the delocalization of electrons from bonding (BD) or lone pair (LP) to anti-bonding (BD)* [40]. Bonding BD shows the condition of the atom that is bonded to other atoms. The Lone Pair symbol LP shows a lone pair on the 
associated atom, and the Rydberg symbol RY indicates the type of atomic orbital with the highest quantum number and energy [41]. Metal atoms and vice versa metal atoms can provide a back donation to the inhibitor. Table 7 shows the $E^{2}$ value from the NBO analysis using the DFT method. The order of $E^{2}$ values is $\mathrm{OCH}_{3}>\mathrm{CH}_{3}>\mathrm{H}>\mathrm{NO}_{2}$. The $\mathrm{OCH}_{3}$ has the highest $E^{2}$ value compared to other substituents, $51.19 \mathrm{kcal} \cdot \mathrm{mol}^{-1}$, which indicates that the interaction between the electron pair (LP) of the $\mathrm{N}(8)$ atom and the Fe (30) atom forms the strongest bond. The $\mathrm{N}(8)$ donates electrons to Fe (30); besides, $\mathrm{N}(8)$ atoms can also accept electrons from $\mathrm{Fe}(30)$ or back donations, but the $E^{2}$ back donation value is relatively small. Substituent $\mathrm{OCH}_{3}$ has the greatest effect on increasing corrosion inhibition efficiency compared to other substituents because it has the highest $E^{2}$.

Table 7. Natural Bonding Orbital NBO analysis of substituted pyrazolone.

\begin{tabular}{|c|c|c|c|c|}
\hline$-\mathbf{R}$ & Donor $(i)$ & $\rightarrow$ & $\operatorname{Acceptor}(j)$ & $E^{2}\left(\mathrm{kcal} \cdot \mathrm{mol}^{-1}\right)$ \\
\hline \multirow[t]{5}{*}{$\mathbf{H}$} & LP(1) N8 & $\rightarrow$ & $\mathrm{LP} *(3) \mathrm{Fe} 26$ & 43.24 \\
\hline & LP(1) N15 & $\rightarrow$ & $\mathrm{LP}^{*}(4) \mathrm{Fe} 26$ & 21.85 \\
\hline & $\mathrm{BD}(1) \mathrm{C} 12-\mathrm{N} 15$ & $\rightarrow$ & $\mathrm{LP}^{*}(4) \mathrm{Fe} 26$ & 9.60 \\
\hline & LP*(3) Fe26 & $\rightarrow$ & $R Y^{*}(10) \mathrm{N} 8$ & 9.03 \\
\hline & $\mathrm{LP}^{*}(3) \mathrm{Fe} 26$ & $\rightarrow$ & RY*(3) N15 & 3.22 \\
\hline \multirow[t]{5}{*}{$\mathrm{CH}_{3}$} & LP(1) N8 & $\rightarrow$ & LP*(4) Fe29 & 49.92 \\
\hline & LP(1) N15 & $\rightarrow$ & $\mathrm{LP} *(5) \mathrm{Fe} 29$ & 27.61 \\
\hline & $\mathrm{BD}(1) \mathrm{N} 12-\mathrm{N} 15$ & $\rightarrow$ & $\mathrm{LP}^{*}(5) \mathrm{Fe} 29$ & 10.59 \\
\hline & $\mathrm{LP}^{*}$ (4) Fe29 & $\rightarrow$ & $\mathrm{RY}^{*}(10) \mathrm{N} 8$ & 8.65 \\
\hline & $\mathrm{LP}^{*}(4) \mathrm{Fe} 29$ & $\rightarrow$ & $\mathrm{RY}^{*}(10) \mathrm{N} 15$ & 3.21 \\
\hline \multirow[t]{6}{*}{$\mathrm{OCH}_{3}$} & LP(1) N8 & $\rightarrow$ & $\mathrm{LP}^{*}(4) \mathrm{Fe} 30$ & 51.19 \\
\hline & LP(1) N15 & $\rightarrow$ & $\mathrm{LP}^{*}(5) \mathrm{Fe} 30$ & 28.91 \\
\hline & BD(1) C9-C10 & $\rightarrow$ & $\mathrm{LP}^{*}(6) \mathrm{Fe} 30$ & 8.27 \\
\hline & $\mathrm{BD}(1) \mathrm{N} 12-\mathrm{N} 15$ & $\rightarrow$ & $\mathrm{LP}^{*}(5) \mathrm{Fe} 30$ & 10.50 \\
\hline & LP*(4) Fe30 & $\rightarrow$ & $\mathrm{RY}^{*}(2) \mathrm{N} 15$ & 3.30 \\
\hline & $\mathrm{LP} *(4) \mathrm{Fe} 30$ & $\rightarrow$ & $\mathrm{RY}^{*}(10) \mathrm{N} 8$ & 8.93 \\
\hline \multirow[t]{6}{*}{$\mathrm{NO}_{2}$} & LP(1) C6 & $\rightarrow$ & LP* (3)Fe28 & 16.01 \\
\hline & LP(1) N8 & $\rightarrow$ & $\mathrm{LP}^{*}(3) \mathrm{Fe} 28$ & 31.07 \\
\hline & $\mathrm{BD}(1) \mathrm{C} 1-\mathrm{C} 6$ & $\rightarrow$ & $\mathrm{LP} *(4) \mathrm{Fe} 28$ & 7.90 \\
\hline & $\mathrm{BD}(1) \mathrm{C} 9-\mathrm{C} 10$ & $\rightarrow$ & $\mathrm{LP} *(5) \mathrm{Fe} 28$ & 8.74 \\
\hline & $\mathrm{LP}(2) \mathrm{Fe} 28$ & $\rightarrow$ & RY* (1) C6 & 8.63 \\
\hline & $\mathrm{LP}(2) \mathrm{Fe} 28$ & $\rightarrow$ & $\mathrm{RY}^{*}(11) \mathrm{N} 8$ & 4.73 \\
\hline
\end{tabular}



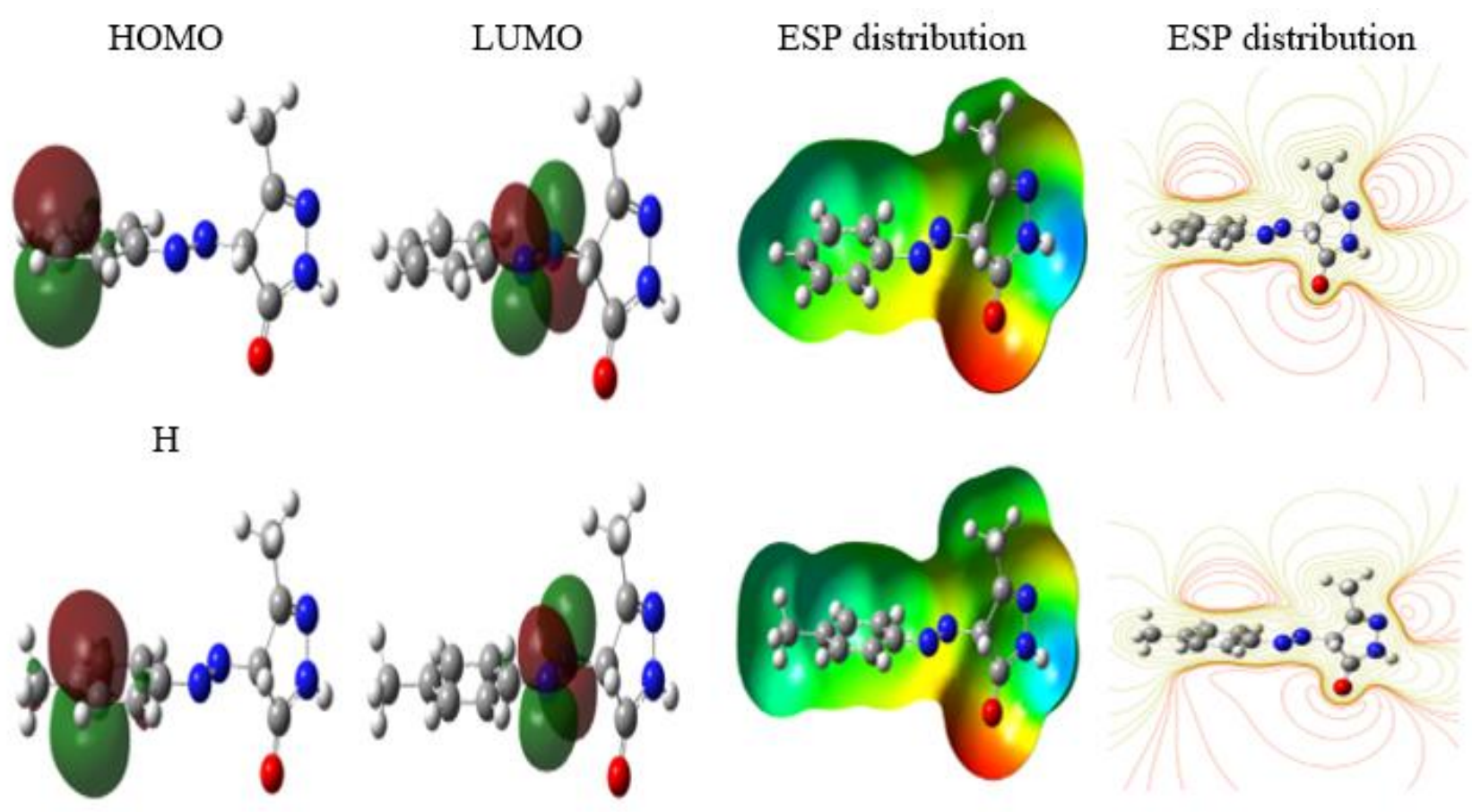

$\mathrm{CH}_{3}$
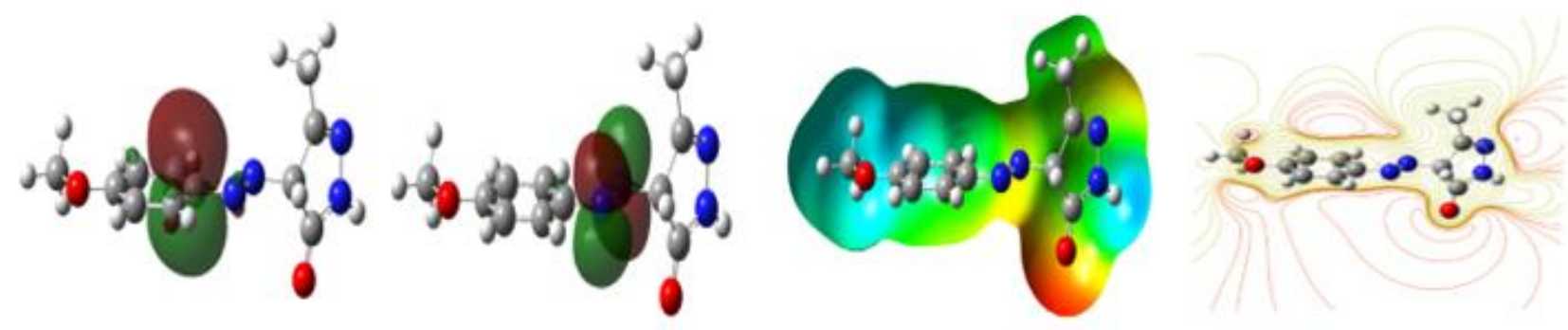

$\mathrm{OCH}_{3}$
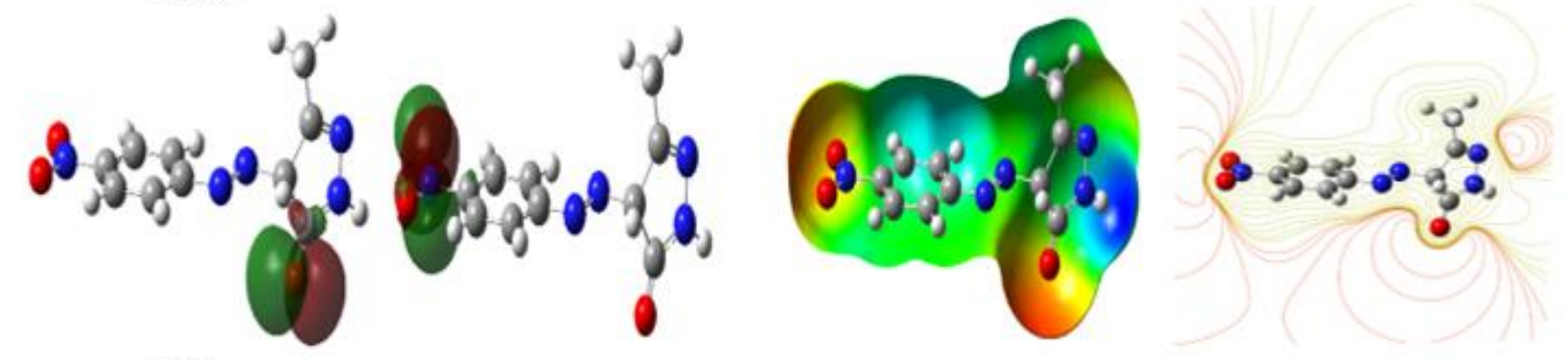

$\mathrm{NO}_{2}$

Figure 5. Visualization of HOMO, LUMO orbitals, and ESP distribution of pyrazolone derivatives.

The quantum chemical parameters are not sufficient to predict the corrosion inhibition mechanism of the targeted inhibitor. Therefore, it is essential to carry out molecular simulations of the inhibitor interactions with the iron surface in water to mimic actual experimental studies [42]. The interaction between inhibitor and carbon steel can 
theoretically be modeled using Monte Carlo simulation, whereas carbon steel can be represented by Fe surface (110) [43] can be seen in Figure 6. Monte Carlo simulation helps find the adsorption site on the metal surface by finding the low energy adsorption site on periodic and non-periodic substrates or by investigating the preferential adsorption of a mixture of adsorbate components [44]. Molecular simulation studies are designed to test the relationship between the inhibitor and the metal surface. The lowest energy configuration value is the most stable adsorption energy of the inhibitor in the $\mathrm{Fe}(110) / 100 \mathrm{H}_{2} \mathrm{O}$ system using Monte Carlo simulations. The analysis results on the shortest bond length of the inhibitor active site bond with ferrous metal measuring less than $3.50 \mathrm{~A}$, which indicates that the formation of a thin layer of the inhibitor is firmly attached to the Fe surface $[45,46]$. Table 8 shows the inhibitor with the $\mathrm{OCH}_{3}$ substituent giving the maximum adsorption energy during the simulation process. It explains the highest inhibition obtained from the maximum electron-acceptor donation of $\mathrm{OCH}_{3}$ during its interaction with the metal surface. The empty d-orbitals of Fe tend to fill with electrons. The pyrazolone derivative has several lone pair electrons containing $\mathrm{O}$ and $\mathrm{N}$ atoms making it possible to supply the unoccupied Fe orbital electrons to form stable coordination bonds. Therefore, the studied molecules tend to adsorb on the Fe surface to create a stable adsorption layer and protect the ferrous metal from corrosion [42]. Figure 7 and show the neutral and protonated adsorption of the pyrazolone derivative on a $\mathrm{Fe}(110)$ surface. The correlation between each system's adsorption energy with quantum parameters can be seen in Figures 7 and 8 . The higher the adsorption energy, the stronger the adsorption [26]. The results showed that the adsorption energy value had the order $\mathrm{OCH}_{3}>\mathrm{CH}_{3}>\mathrm{H}>\mathrm{NO}_{2}$ as well as the protonated molecular concentration $\mathrm{OCH}_{3}>\mathrm{CH}_{3}>\mathrm{H}>\mathrm{NO}_{2}$.
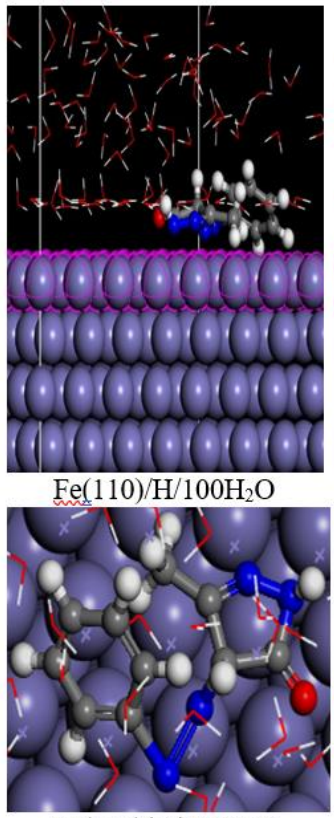

$\mathrm{Fe}(110) / \mathrm{H} / 100 \mathrm{H}_{2} \mathrm{O}$
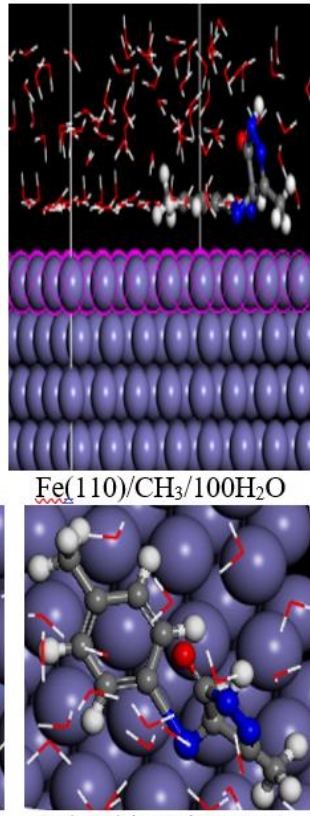

$\mathrm{Fe}(110) / \mathrm{CH}_{3} / 100 \mathrm{H}_{2} \mathrm{O}$
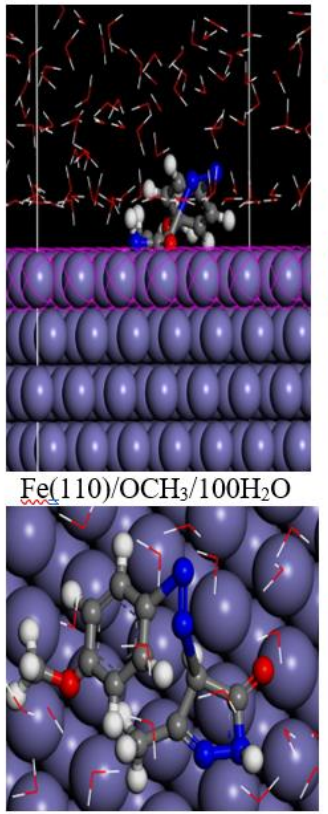

$\mathrm{Fe}(110) / \mathrm{OCH}_{3} / 100 \mathrm{H}_{2} \mathrm{O}$
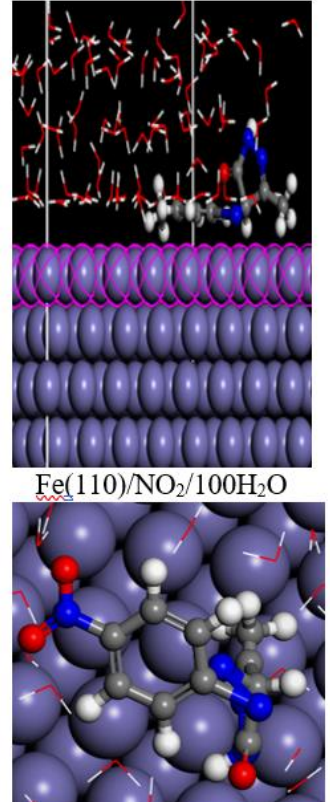

$\mathrm{Fe}(110) / \mathrm{NO}_{2} / 100 \mathrm{H}_{2} \mathrm{O}$

Figure 6. Adsorption of pyrazolone derivatives on metal surfaces in the Metropolis Monte Carlo simulation system of $\mathrm{Fe}(110) /$ inhibitors $/ 100 \mathrm{H}_{2} \mathrm{O}$. 
Table 8. Adsorption energy of $\mathrm{Fe}(110) /$ inhibitor $/ 100 \mathrm{H}_{2} \mathrm{O}$ system with Monte Carlo simulation.

\begin{tabular}{ccc}
\hline Systems & $\begin{array}{c}\text { Adsorption energy (inhibitors) } \\
\mathbf{k J} \cdot \mathbf{m o l}^{-\mathbf{1}}\end{array}$ & $\begin{array}{c}\text { Adsorption energy (water) } \\
\mathbf{k J} \cdot \mathbf{m o l}^{-\mathbf{1}}\end{array}$ \\
\hline Neutral Inhibitor & & \\
\hline $\mathrm{Fe}(110) / \mathrm{H} / 100 \mathrm{H}_{2} \mathrm{O}$ & -122.5352397 & -15.76164044 \\
$\mathrm{Fe}(110) / \mathrm{CH}_{3} / 100 \mathrm{H}_{2} \mathrm{O}$ & -141.7897695 & -15.78956165 \\
$\mathrm{Fe}(110) / \mathrm{OCH}_{3} / 100 \mathrm{H}_{2} \mathrm{O}$ & -145.5193466 & -14.01906377 \\
$\mathrm{Fe}(110) / \mathrm{NO}_{2} / 100 \mathrm{H}_{2} \mathrm{O}$ & -96.90984619 & -15.88215498 \\
\hline $\mathrm{Protonated} \mathbf{I n h i b i t o r}$ & & -15.04476745 \\
$\mathrm{Fe}(110) / \mathrm{H} / 100 \mathrm{H}_{2} \mathrm{O}$ & -136.1514453 & -15.04068854 \\
$\mathrm{Fe}(110) / \mathrm{CH}_{3} / 100 \mathrm{H}_{2} \mathrm{O}$ & -138.6204407 & -15.48264385 \\
$\mathrm{Fe}(110) / \mathrm{OCH}_{3} / 100 \mathrm{H}_{2} \mathrm{O}$ & -141.2104533 & -15.77661008 \\
$\mathrm{Fe}(110) / \mathrm{NO}_{2} / 100 \mathrm{H}_{2} \mathrm{O}$ & -129.1357282 & \\
\hline
\end{tabular}
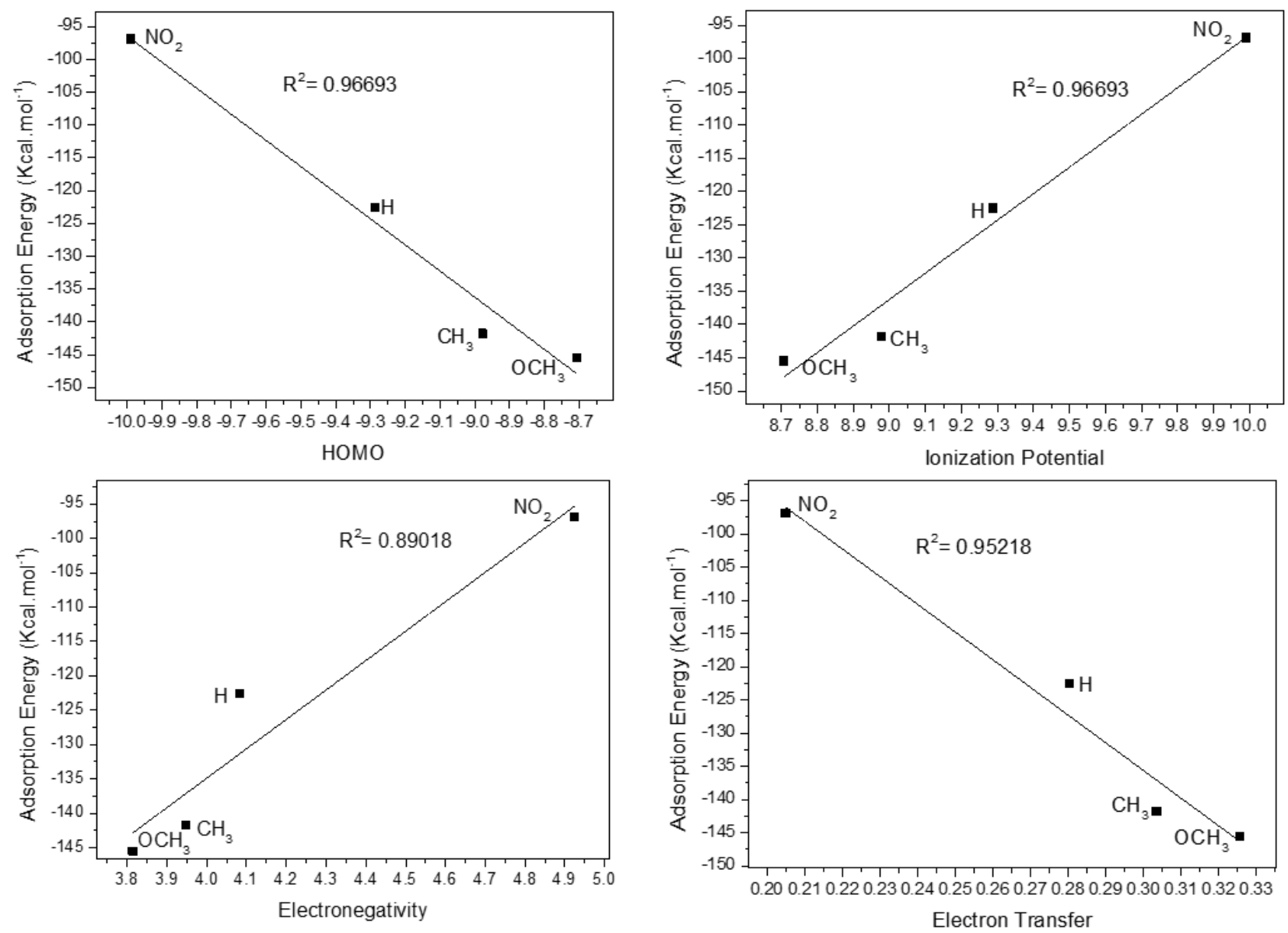

Figure 7. Relationship between adsorption energy and quantum parameters (HOMO, ionization potential, electronegativity, and electron transfer) of neutral inhibitors. 

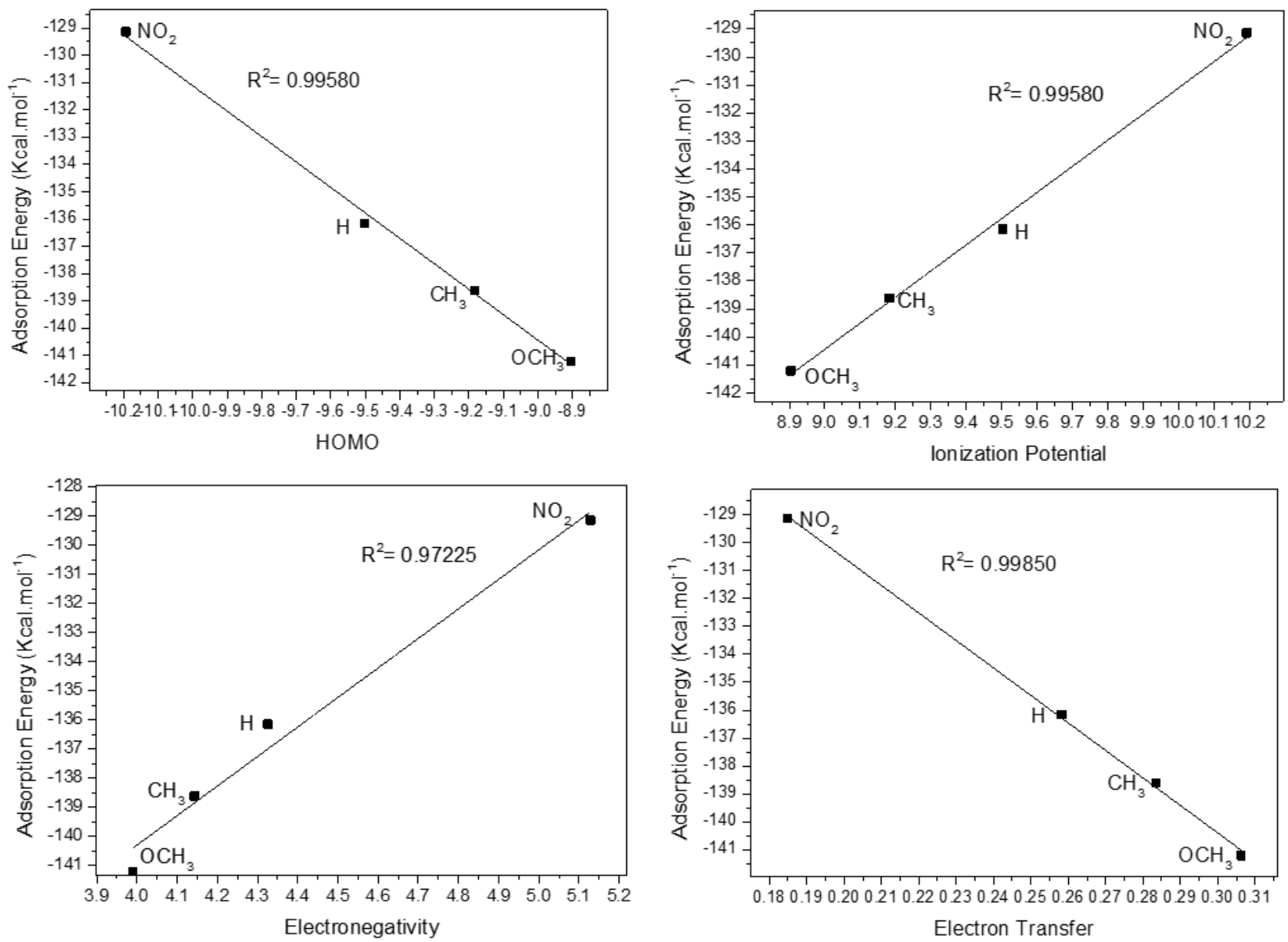

Figure 8. Relationship between adsorption energy and quantum parameters (HOMO, ionization potential, electronegativity, and electron transfer) of protonated inhibitors.

\section{Conclusion}

The theoretical study of DFT, ab initio, and MC simulation were applied to provide a detailed description of pyrazolone derivatives' corrosion inhibition mechanism. The effect of substituents $\left(\mathrm{CH}_{3}, \mathrm{OCH}_{3}\right.$, and $\left.\mathrm{NO}_{2}\right)$ on the efficiency of corrosion inhibition against carbon steel is studied in more detail. Quantum chemical parameters such as frontier molecular orbitals, ionization potential, electronegativity, and electron transfer affect corrosion inhibition efficiency. The quantum chemical parameters show that the electron donor group increases the order $\mathrm{OCH}_{3}>\mathrm{CH}_{3}>\mathrm{H}>\mathrm{NO}_{2}$. These results are consistent with experimental studies that have been previously reported by Fouda et al. The analysis of the Fukui function shows that the active site of the pyrazolone derivative is at atoms $\mathrm{C}(1), \mathrm{C}(10)$, $\mathrm{N}(7), \mathrm{N}(8)$ and $\mathrm{O}(18)$. The atom is predominantly involved in the inhibitor interaction with the metal surface. The value of selected stabilization energy $\left(E^{2}\right)$ was obtained as $51.19 \mathrm{kcal} / \mathrm{mol}$ from the $\mathrm{OCH}_{3}$ substituent. It shows that the $\mathrm{OCH}_{3}$ substituent contributes maximally to corrosion inhibition. The natural bonding orbital analysis results are in line with the results of the MC simulations for inhibitor interaction with the metal surface. This theoretical study is expected to help bridge the gap between experimental studies in 
providing a detailed description of the interaction mechanism between inhibitors and metal surfaces.

\section{References}

1. Y. Xu, L. Liu, Q. Zhou, X. Wang and Y. Huang, Understanding the influences of precorrosion on the erosion-corrosion performance of pipeline steel, Wear, 2020, 442, 203151. doi: 10.1016/j.wear.2019.203151

2. D. Dwivedi, K. Lepková and T. Becker, Carbon steel corrosion: a review of key surface properties and characterization methods, RSC $A d v ., 2017$, 7, 4580-4610. doi: 10.1039/C6RA25094G

3. D.A. Winkler, Predicting the performance of organic corrosion inhibitors, Metals, 2017, 7, no. 12, 553. doi: $10.3390 /$ met 7120553

4. C. Verma, L.O. Olasunkanmi, Eno E. Ebenso and M.A. Quraishi, Substituents effect on corrosion inhibition performance of organic compounds in aggressive ionic solutions: a review, J. Mol. Liq., 2018, 251, 100-118. doi: 10.1016/j.molliq.2017.12.055

5. O. Kaczerewska, R. Leiva-Garcia, R. Akid, B. Brycki, I. Kowalczyk and T. Pospieszny, Heteroatoms and $\pi$ electrons as favorable factors for efficient corrosion protection, Mater. Corros., 2019, 70, 1099-1110. doi: 10.1002/maco.201810570

6. D.K. Verma, Y. Dewangan, A.K. Dewangan and A. Asatker, Heteroatom-Based Compounds as Sustainable Corrosion Inhibitors: An Overview, J. Bio Tribo Corrosion, 2021, 7, 1-18. doi: 10.1007/s40735-020-00447-7

7. M. Athar, H. Ali and M.A. Quraishi, Corrosion inhibition of carbon steel in hydrochloric acid by organic compounds containing heteroatoms, Br. Corros. J., 2002, 37, 155-158. doi: $10.1179 / 000705902225002376$

8. S. Hadisaputra, A.A. Purwoko, I. Ilhamsyah, S. Hamdiani, D. Suhendra, N. Nuryono, B. Bundjali, A combined experimental and theoretical study of (E)-ethyl 3-(4methoxyphenyl) acrylate as corrosion inhibitor of iron in $1 \mathrm{M} \mathrm{HCl}$ solutions, Int. J. Corros. Scale Inhib., 2018, 7, no. 4, 633-647. doi: 10.17675/2305-6894-2018-7-4-10

9. S. Hadisaputra, A.A. Purwoko, Rahmawati, D. Asnawati, I.S. Hamdiani and Nuryono, Experimental and Theoretical Studies of (2R)-5-hydroxy-7-methoxy-2-phenyl-2,3dihydrochromen-4-one as corrosion inhibitor for Iron in Hydrochloric Acid, Int. J. Electrochem. Sci., 2019, 14, 11110-11121. doi: 10.20964/2019.12.77

10. S. Hadisaputra, A.A. Purwoko, A. Hakim, R. Wati, D. Asnawati and Y.P. Prananto, Experimental and Theoretical Study of Pinostrobin as Copper Corrosion Inhibitor at $1 \mathrm{M}$ $\mathrm{H}_{2} \mathrm{SO}_{4}$ Medium, IOP Conf. Ser. Mater. Sci. Eng., 2020, 833, no. 012010. doi: $\underline{10.1088 / 1757-899 X / 833 / 1 / 012010}$

11. C. Verma, L.O. Olasunkanmi, E.E. Ebenso and M.A. Quraishi, Substituents effect on corrosion inhibition performance of organic compounds in aggressive ionic solutions: a review, J. Mol. Liq., 2018, 251, 100-118. doi: 10.1016/j.molliq.2017.12.055 
12. S. Hadisaputra, A.A. Purwoko, F. Wajdi, I. Sumarlan and S. Hamdiani, Theoretical study of the substituent effect on corrosion inhibition performance of benzimidazole and its derivatives, Int. J. Corros. Scale Inhib., 2019, 8, no. 3, 673-688. doi: 10.17675/23056894-2019-8-3-15

13. K. Cao, W. Li and L. Yu, Investigation of 1-Phenyl-3-Methyl-5-Pyrazolone as a corrosion inhibitor for mild steel in $1 \mathrm{M}$ hydrochloric acid, Int. J. Electrochem. Sci., 2012, 7, 806-818.

14. Y. Zhang, Y. Cheng, F. Ma and K. Cao, Corrosion Inhibition of Carbon Steel by 1Phenyl-3-Amino-5-Pyrazolone in $\mathrm{H}_{2} \mathrm{SO}_{4}$ solution, Int. J. Electrochem. Sci., 2019, 14, 999-1008. doi: $\underline{10.20964 / 2019.01 .69}$

15. A.S. Fouda, A.A. Al-Sarawy and E.E. El-Katori, Pyrazolone derivatives as corrosion inhibitors for C-steel in hydrochloric acid solution, Desalination, 2006, 201, 1-13. doi: 10.1016/i.desal.2006.03.519

16. S. Hadisaputra, A.A. Purwoko, A. Hakim, L.R.T. Savalas, R. Rahmawati, S. Hamdiani and N. Nuryono, ab initio MP2 and DFT studies of ethyl-p-methoxycinnamate and its derivatives as corrosion inhibitors of iron in acidic medium, J. Phys.: Conf. Ser., 2019, 1402, no. 055046. doi: 10.1088/1742-6596/1402/5/055046

17. G. Piccini, M. Alessio and J. Sauer, ab initio calculation of rate constants for moleculesurface reactions with chemical accuracy, Angew. Chem., Int. Ed., 2016, 55, 5235-5237. doi: 10.1002/anie.201601534

18. S. Hadisaputra, A.A. Purwoko, Y. Wirayani, M. Ulfa and S. Hamdiani, Density functional and perturbation calculation on the corrosion inhibition performance of benzylnicotine and its derivatives, AIP Conf. Proc., 2020, 2243, no. 020006. doi: $\underline{10.1063 / 5.0001077}$

19. N. Ammouchi, H. Allal, Y. Belhocine, S. Bettaz and E. Zouaoui, DFT computations and molecular dynamics investigations on conformers of some pyrazinamide derivatives as corrosion inhibitors for aluminum, J. Mol. Liq., 2020, 300, no. 112309. doi: 10.1016/j.molliq.2019.112309

20. S. Hadisaputra, A.A. Purwoko, L.R.T. Savalas, N. Prasetyo, E. Yuanita, S. Hamdiani, Quantum Chemical and Monte Carlo Simulation Studies on Inhibition Performance of Caffeine and Its Derivatives against Corrosion of Copper, Coatings, 2020, 10, no. 11, 1086. doi: $10.3390 /$ coatings 10111086

21. M.J. Frisch, G.W. Trucks, H.B. Schlegel, G.E. Scuseria, M.A. Robb, J.R. Cheeseman, G. Scalmani, V. Barone, B. Mennucci, G.A. Petersson, H. Nakatsuji, M. Caricato, X. Li, H.P. Hratchian, A.F. Izmaylov， J. Bloino， G. Zheng， J.L. Sonnenberg， M. Hada, M. Ehara, K. Toyota, R. Fukuda, J. Hasegawa, M. Ishida, T. Nakajima, Y. Honda, O. Kitao, H. Nakai, T. Vreven, J.A. Montgomery, Jr., J.E. Peralta, F. Ogliaro, M. Bearpark， J.J. Heyd， E. Brothers， K.N. Kudin， V.N. Staroverov， R. Kobayashi, J. Normand, K. Raghavachari, A. Rendell, J.C. Burant, S.S. Iyengar, J. Tomasi, M. Cossi, N. Rega， J.M. Millam, M. Klene, J.E. Knox, J.B. Cross, V. Bakken, C. Adamo, J. Jaramillo, R. Gomperts, R.E. Stratmann, O. Yazyev, A.J. Austin, R. Cammi, 
C. Pomelli, J.W. Ochterski, R.L. Martin, K. Morokuma, V.G. Zakrzewski, G.A. Voth, P. Salvador, J.J. Dannenberg, S. Dapprich, A.D. Daniels, Ö. Farkas, J.B. Foresman, J.V. Ortiz, J. Cioslowski and D.J. Fox, Gaussian 09, Revision C.01, Gaussian, Inc., Wallingford CT, 2009.

22. T. Koopmans, Über die Zuordnung von Wellenfunktionen und Eigenwerten zu den einzelnen Elektronen eines Atoms, Physica, 1934, 1, 104-113. doi: 10.1016/S00318914(34)90011-2

23. A.Y. Musa, A.B. Mohamad, A.A. H. Kadhum, M.S. Takriff and W. Ahmoda, Quantum chemical studies on corrosion inhibition for series of thio compounds on mild steel in hydrochloric acid, J. Ind. Eng. Chem., 2012, 18, 551-555. doi: 10.1016/j.jiec.2011.11.131

24. N. Islam and D. Chandra Ghosh, A new algorithm for the evaluation of the global hardness of polyatomic molecules, Mol. Phys., 2011, 109, 917-931. doi: $10.1080 / 00268976.2011 .558856$

25. R.G. Parr, L.V. Szentpaly and S. Liu, Electrophilicity index, J. Am. Chem. Soc., 1999, 121, no. 9, 1922-1924. doi: $10.1021 /$ ja983494x

26. W. Yang and R.G. Parr, Hardness, softness, and the fukui function in the electronic theory of metals and catalysis, Proc. Natl. Acad. Sci., 1985, 82, no. 20, 6723-6726. doi: 10.1073/pnas.82.20.6723

27. R.G. Pearson, Hard and soft acids and bases - the evolution of a chemical concept, Coord. Chem. Rev., 1990, 100, 403-425. doi: 10.1016/0010-8545(90)85016-L

28. R.G. Pearson, Absolute electronegativity and hardness: application to inorganic chemistry, Inorg. Chem., 1988, 27, no. 4, 734-740. doi: $10.1021 / \mathrm{ic} 00277 \mathrm{a} 030$

29. V.S. Sastri and J.R. Perumareddi, Molecular orbital theoretical studies of some organic corrosion inhibitors, Corros. Sci., 1997, 53, no. 8, 617-622. doi: 10.5006/1.3290294

30. S. Hadisaputra, L.R. Canaval, H.D. Pranowo and R. Armunanto, Theoretical study of substituent effects on $\mathrm{Cs}^{+} / \mathrm{Sr}^{2+}$-dibenzo-18-crown-6 complexes, Monatsh. Chem., 2014, 145, 737-745. doi: $10.1007 / \mathrm{s} 00706-013-1129-\mathrm{x}$

31. N. Karakus and K. Sayin, The investigation of corrosion inhibition efficiency on some benzaldehyde thiosemicarbazones and their thiole tautomers: Computational study, $J$. Taiwan Inst. Chem. Eng., 2015, 48, 95-102. doi: 10.1016/j.jtice.2014.10.024

32. D. Frenkel and B. Smit, Understanding Molecular Simulations: from Algorithms to Applications, 2nd ed, Academic Press, San Diego, 2002.

33. S. Kirkpatrick, C.D. Gelatt and M.P. Vecchi, Optimization by simulated annealing, Science, 1983, 220, 671-680. doi: 10.1126/science.220.4598.671

34. G.F. de Sousa, C.C. Gatto, I.S. Resck and V.M. Deflon, Synthesis, spectroscopic studies and X-ray Crystal structures of new pyrazoline and pyrazole derivatives, J. Chem. Crystallogr., 2011, 41, 401-408. doi: 10.1007/s10870-010-9896-2

35. J. Main-Bobo, S. Olesik, W. Gase, T. Baer, A.A. Mommers and J.L. Holmes, The thermochemistry and dissociation dynamics of internal-energy-selected pyrazole and imidazole ions, J. Am. Chem. Soc., 1986, 108, no. 4, 677-683. doi: 10.1021/ja00264a018 
36. A. Kokalj and N. Kovačević, On the consistent use of electrophilicity index and HSABbased electron transfer and its associated change of energy parameters, Chem. Phys. Lett., 2011, 507, 181-184. doi: 10.1016/j.cplett.2011.03.045

37. S. Hadisaputra, Z. Iskandar and D. Asnawati, Prediction of the Corrosion Inhibition Efficiency of Imidazole Derivatives: A Quantum Chemical Study, Acta Chim. Asiana, 2019, 2, no. 1, 88-94. doi: 10.29303/aca.v2i1.15

38. N.O. Eddy, S.R. Stoyanov and E.E. Ebenso, Fluoroquinolones as corrosion inhibitors for mild steel in acidic medium; experimental and theoretical studies, Int. J. Electrochem. Sci., 2010, 5, 1127-1150.

39. Y. Wirayani, M. Ulfa and Y. Yahmin, Corrosion inhibition efficiency of nicotine based on quantum chemical study, Acta Chim. Asiana, 2018, 1, no. 2, 37-42. doi: 10.29303/aca.v1i2.29

40. A.S. Fouda, M.A. Ismail, A.S. Abousalem and G.Y. Elewady, Experimental and theoretical studies on corrosion inhibition of 4-amidinophenyl-2,2'-bifuran and its analogues in acidic media, RSC Adv., 2017, 7, 46414-46430. doi: 10.1039/C7RA08092A

41. B.D. Mert, A.O. Yüce, G. Kardaş and B. Yazıc1, Inhibition effect of 2-amino-4methylpyridine on mild steel corrosion: experimental and theoretical investigation, Corros. Sci., 2014, 85, 287-295. doi: 10.1016/j.corsci.2014.04.032

42. Y. Sasikumar, A.S. Adekunle, L.O. Olasunkanmi, I. Bahadur, R. Baskar, M.M. Kabanda, I.B. Obot, E.E. Ebenso, Experimental, quantum chemical and Monte Carlo simulation studies on the corrosion inhibition of some alkyl imidazolium ionic liquids containing tetrafluoroborate anion on mild steel in acidic medium, J. Mol. Liq., 2015, 211, 105118. doi: j.molliq.2015.06.052

43. E.D. Akpan, I.O. Isaac, L.O. Olasunkanmi, E.E. Ebenso and E.S.M. Sherif, Acridinebased thiosemicarbazones as novel inhibitors of mild steel corrosion in $1 \mathrm{M} \mathrm{HCl}$ : synthesis, electrochemical, DFT and Monte Carlo simulation studies, RSC Adv., 2019, 9, 29590-29599. doi: 10.1039/C9RA04778F

44. K.F. Khaled and A. El-Maghraby, Experimental, Monte Carlo and molecular dynamics simulations to investigate corrosion inhibition of mild steel in hydrochloric acid solutions, Arabian J. Chem., 2014, 7, 319-326. doi: 10.1016/j.arabjc.2010.11.005

45. W. Shi, M. Xia, W. Lei and F. Wang, Molecular dynamics study of polyether polyamino methylene phosphonates as an inhibitor of anhydrite crystal, Desalination, 2013, 322, 137-143. doi: 10.1016/j.desal.2013.05.013

46. S.A. Umoren, I.B. Obot, A. Madhankumar and Z.M. Gasem, Effect of degree of hydrolysis of polyvinyl alcohol on the corrosion inhibition of steel: theoretical and experimental studies, J. Adhes. Sci. Technol., 2015, 29, 271-295. doi: $\underline{10.1080 / 01694243.2014 .985281}$ 